\title{
Analysis of Roller Chain Drive System with Multi-Flexible Body Dynamics Methodology
}

\author{
Wasan Suwannahong and Chakrit Suvanjumrat \\ Department of Mechanical Engineering, Faculty of Engineering, Mahidol University, Salaya, Nakorn Pathom, 73170, Thailand \\ Laboratory of Computer Mechanics for Design (LCMD), Department of Mechanical Engineering, Faculty of Engineering, Mahidol University, \\ Salaya, Nakorn Pathom, 73170, Thailand
}

\begin{abstract}
Finite element method (FEM) was employed to analyze the roller chain drive system which complicated to determine various design factors. The multi-flexible body dynamics (MFBD) method was proposed to model and analysis the roller chain drive system. The roller chain which composed of plates, pins and rollers was meshed with solid elements under the convergence test. The eight tooth sprocket was modeled by rigid body to roll and contact with the roller chain. The dynamic load distribution of the roller chain on the rigid sprocket was compared with the analytical solution. The MFBD simulation results had a good agreement with analytic results which obtained an average error of $12.32 \%$.
\end{abstract}

\section{Introduction}

The roller chain has an important role as to transport heavy load of products in along distance of producing line that make wear in chain and sprocket, fracture in chain and drive shaft, chain climbing on sprocket, loud noise chain and elongation of chain. These problems are difficult to predict for design and preventive maintenance of the roller chain to protect the breakdown of the producing line. Many factors consist of load, chain tension, contact force between chain and sprocket, useful life, fatigue, alignment and pretension were considered for the chain design [1]. Unfortunately, the roller chain drive system has a lot of components and large movements therefore the design of roller chain was difficult and complicate by using analytical method.

In recent years, finite element method (FEM) was conducted to analyze the roller chain of many transmission applications [2]-[4]. There was the simple methodology to calculate strength of chain components by static analysis but dynamic effects were still indistinct to determine by FEM. The stress and strain which accurred by the element model were deformed, were the finite element simulation results. The multi body simulation (MBS) had been used for dynamic simulation of the chain drive system. The MBS result obtained chain velocity, impulsive and meshing area because the rigid body of chain components was employed for simulation [5], [6]. To calculate load and strength on the dynamic behavior chain simultaneously, the integration between FEM and MBS which known as the multi-flexible body dynamic (MFBD) had developed [7]-[9]. This research had apllied MFBD to analyze the roller chain drive system. The MFBD methodology would be useful to design and predict lift time of the roller chain for the producing line in a further work.

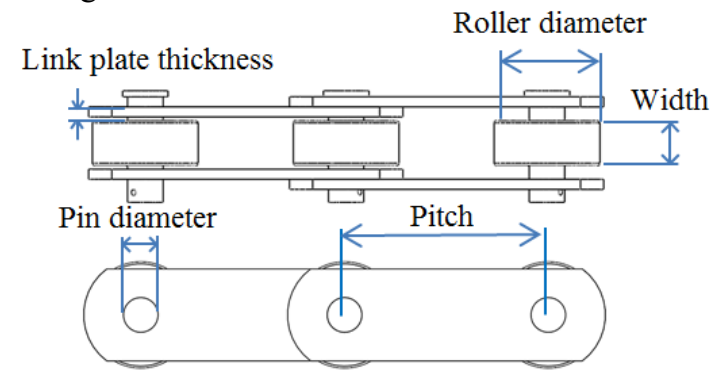

(a)

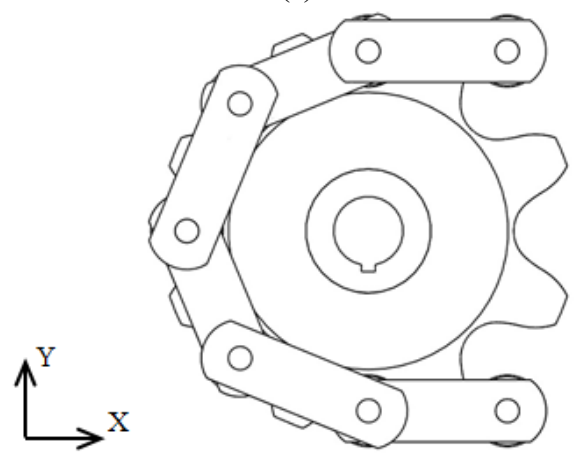

(b)

Figure 1. CAD model description of: (a) roller chain and (b) roller chaindrive system

\section{Analytical method}

The dynamic load distribution in the roller chain was calculated following assumptions: (a) the pitch of the roller chain was equal to the pitch of sprocket; (b) all 
rollers contacting was seated on the sprocket tooth; (c) no mechanical tolerances were present; and (d) the chain weight was negligible [10]. The component of the roller chain which was included in analytical method composed of cylindrical pins, link plates and rollers. The roller chain had pitch, link plate thickness, roller diameter, pin diameter and width of 100.00, 5.00, 52.00, 17.00 and $22.00 \mathrm{~mm}$ respectively (Fig. 1a). The sprocket tooth profile was modeled by parameters which comprised of a pitch diameter of $100 \mathrm{~mm}$, a tooth thickness of $43 \mathrm{~mm}$, a dedendum of $26.13 \mathrm{~mm}$, an addendum of $20.05 \mathrm{~mm}$ and seating curve diameter of $52 \mathrm{~mm}$ [11]. The roller chain which engaged with an eight-tooth sprocket was illustrated by computer aided design (CAD) model in Fig. 1b. The roller and sprocket of the roller chain drive system had been depicted by the free body diagram as shown in Fig. 2. The sprocket was rotated in a clockwise, therefore the tension $T_{t}$ and $T_{s}$ was the tight and slack side of chain tensions $\left(T_{i}\right)$ respectively. The rollers were in the seated position and contacted the tight flank of the sprocket tooth, therefore tooth loads $\left(P_{i}\right)$ were acted on rollers and passed through center of rollers. The chain rollers were numbered $\mathrm{i}$ started from the tight side to the slack side or the counterclockwise direction. The pressure angle $(\theta)$ and articulation angle $(\alpha)$ also were described in Fig. 2. The link of the tight and slack strand made an angle $\xi$ and $\varepsilon$ respectively. The effect of friction force $\left(F_{i}\right)$ had changed the pressure angle by a friction angle $(\delta)$. The free body diagram of chain rollers (Fig. 3) under equilibrium consideration had relative equations between tooth load and chain tension assuming as following:

$P_{i}=\frac{T_{i-1}-T_{i} \cos \alpha}{\cos \left(\theta_{i}-\delta_{i}\right)}, i=1,2,3, \ldots, n$

$P_{i}=\frac{T_{i}-T_{i+1} \cos \alpha}{\cos \left(\theta_{i+1}-\delta_{i+1}\right)}, i=1,2,3, \ldots, n$

$P_{i}=\frac{T_{i} \sin \alpha}{\sin \left(\theta_{i}-\delta_{i}\right)}, i=1,2,3, \ldots, n$

$P_{i+1}=\frac{T_{i+1} \sin \alpha}{\sin \left(\theta_{i+1}-\delta_{i+1}\right)}, i=1,2,3, \ldots, n$

$T_{0}=T_{t} \frac{\sin \left(\theta-\delta_{1}\right)}{\sin \left(\theta+\xi-\delta_{1}\right)}$

$T_{s}=T_{n} \frac{\sin \left(\theta-\delta_{1}\right)}{\sin \left(\theta+\varepsilon-\delta_{1}\right)}$

$\delta=\tan ^{-1}\left(\mu_{v}\right)$

where $\mu_{v}$ is the dynamic coefficient

\section{Multi-Flexible body dynamics method}

The CAD model of roller chain components had been meshed with solid elements by using commercial software, MSC.Patran. The flexible roller chain under the convergence test was obtained 173,298 elements. The material properties of roller chain composed of elastic modulus, poisson ratio and density at $210 \mathrm{GPa}, 0.3$ and $7,800 \mathrm{~kg} / \mathrm{m}^{3}$ respectively. The Craig-Bampton modal synthesis method in MSC.Nastran was performed to obtain model neural file (MNF), a binary file relating to a flexible body, of chain components. A sprocket surface was defined by a rigid body and assembled to MNF of roller chain components in MSC.Adams. The roller chain drive system model which was generated in MSC.Adams shown in Fig. 4. The four flexible chian links were meshed to an eight-tooth sprocket on the initial position that made angle between the tight chain link and slack chain link at 0 degree.

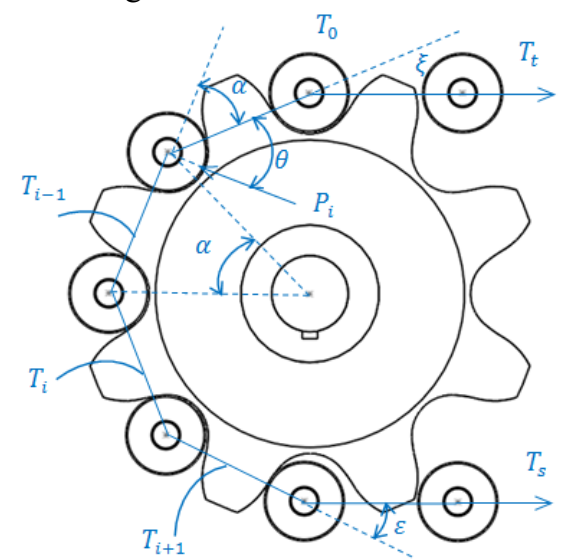

Figure 2. Free body diagram of chain rollers seating on a sprocket.

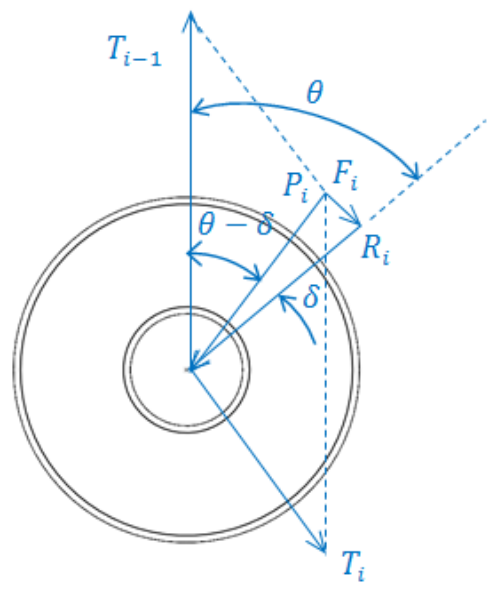

Figure 3. Free body diagram of a chain roller.

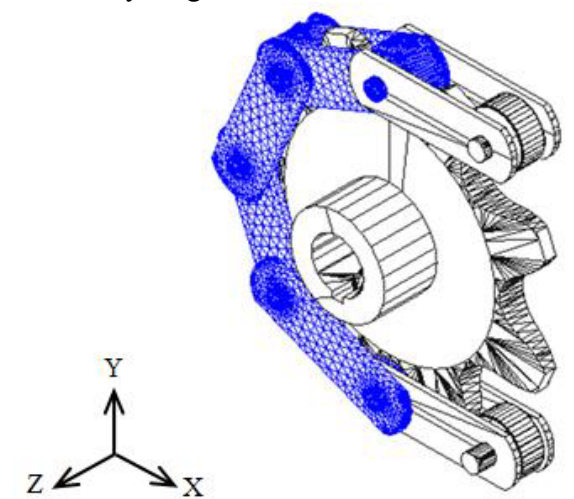

Figure 4. FE model of roller chain engaing with $\mathrm{CAD}$ model of a sprocket.

The tight and slack chain link still were the rigid body because they were specified velocity and tension force (assumption of chain weight) respectively. This study 
case shown that the tight chain link had velocity of 400 $\mathrm{mm} / \mathrm{s}$ and the slack chain link had load of 2,000 N. The contact parameter was defined on contact of $1 \times 10^{5}$ $\mathrm{N} / \mathrm{mm}$, a force exponent of 2.2 , a damping of $10 \mathrm{Ns} / \mathrm{mm}$ and a penetration depth of $0.1 \mathrm{~mm}$. The Gear Stiff Integrator (GSTIFF) which was solver in MSC.Adams [12] employed to calculate dynamic response of the roller chain drive system.

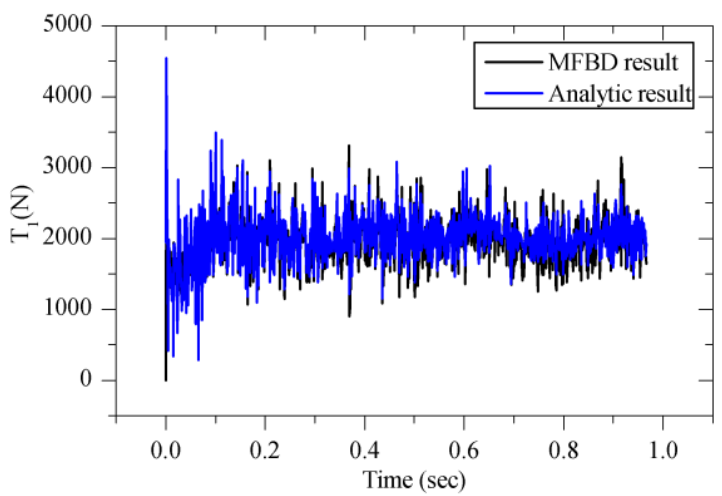

Figure 5. Tension force of chain link no. 1.

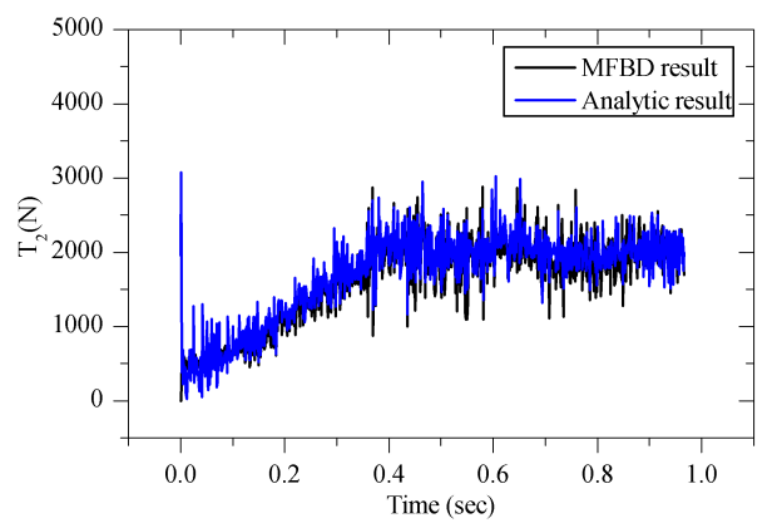

Figure 6. Tension force of chain link no. 2.

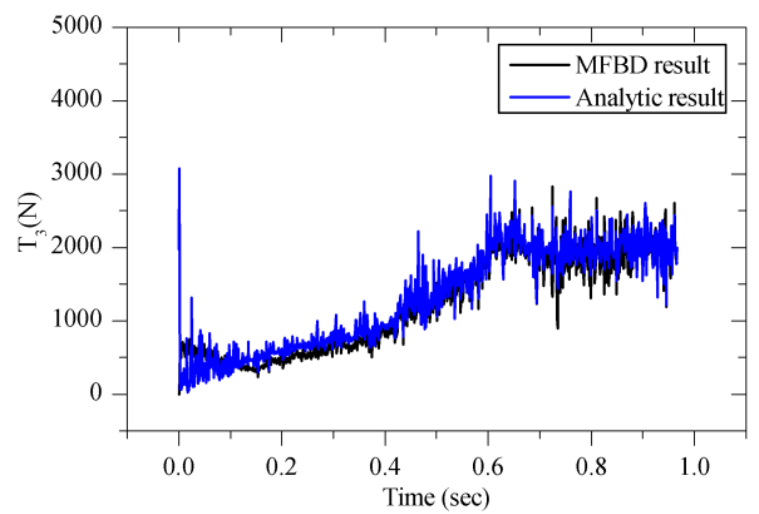

Figure 7. Tension force of chain link no. 3.

\section{Results and discussion}

The dynamic tension force result by using the MFBD simulation was compared with the analytical result. The comparison of tension forces $T_{1}$ to $T_{4}$ (starting from flexible link of tight side) were shown in Fig. 5 to Fig. 8 respectively. The tension force of the first flexible chain link was started about $2,000 \mathrm{~N}$ from the initial time because of the initial condition calculation. The second chain link had the maximum tension force led the third flexible chain link of $0.2 \mathrm{sec}$. The fouth link supported the maximum force of $2,000 \mathrm{~N}$ when the rotating time was $0.85 \mathrm{sec}$. All of chain links supported the maximum tension force when rotated at twelve o'clock of a sprocket. The magnitude of simulated tension force $T_{1}, T_{2}, T_{3}$ and $T_{4}$ which happened at the same time of the analytic solution had an average error of $9.99,15.87,13.62$ and $9.82 \%$ respectively. The errors might be that the assumption of analytic method was negligible the chain weight therefore it had value less than the simulation result. The chain moving related with the sprocket rotating shown by sequent images in Fig. 9. The results of the MFBD simulation could be illustrated by stress contour on a flexible roller chain by red; maximum von mises stress and blue; minimum von mises stress that occurred when the flexible chain was deformed by tension and impact force. The maximum stress always occurred on chain links and rollers when it rotated at twelve o'clock position of a sprocket. This position happened the maximum tension force on chain links. The area where near the pin holes of chain links occured red color when rotated to twelve o'clock position of a sprocket. The von mises stress had a peak value and reduced after chain links left of twelve o'clock position. This phenomenon that happened on the chain links was induced the cyclic stress and strain on the chain and the sprocket system.

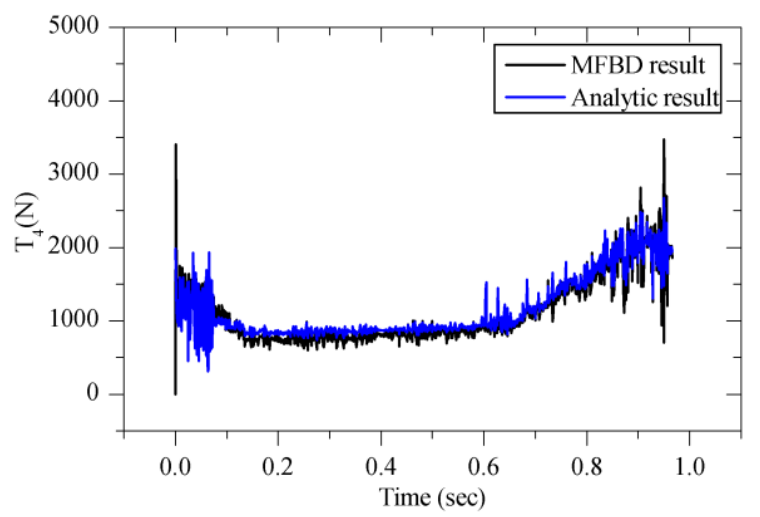

Figure 8. Tension force of chain link no. 4.

The chain roller impacted sprocket tooth during a sprocket drove a roller chain. The impact force between rollers of chain and sprocket tooth which occurred on the second roller of the tight side were indicated by $P_{l}$. The third roller to fifth roller were indicated by $P_{2}$ to $P_{4}$, respectively. The dynamic force $P_{1}, P_{2}, P_{3}$ and $P_{4}$ during rotation of the sprocket shown by a graph in Fig. 10. The impact force was periodic and increased to the maximum value of $2,337.45 \mathrm{~N}$ when rollers fully seated on the sprocket tooth and decreased almost to zero when rollers left the sprocket. The speed of a roller chain increased the impact force which was more than the drag load on the slack chain link of 1.17 times. The graph of impact force of roller no. 5 (Fig. 10) shown the cyclic form distincly because it was started from six o'clock to twelve o'clock position of the sprocket for the MFBD simulation. This impact force was a good result for leading to calculate strength of sprocket tooth. 


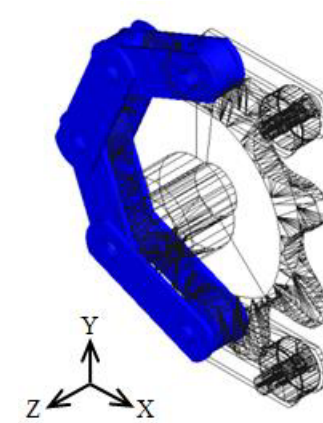

(a)

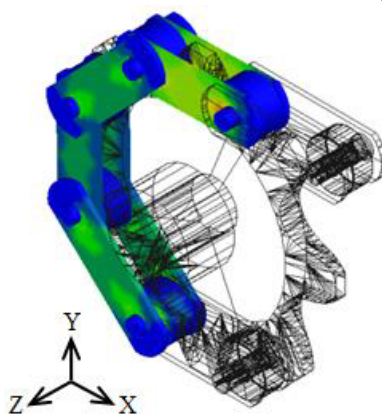

(b)

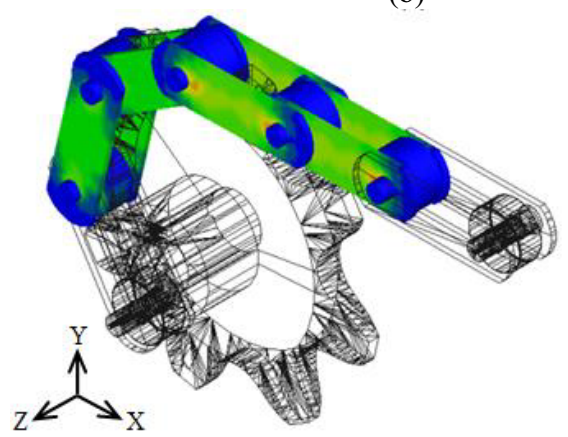

(c)
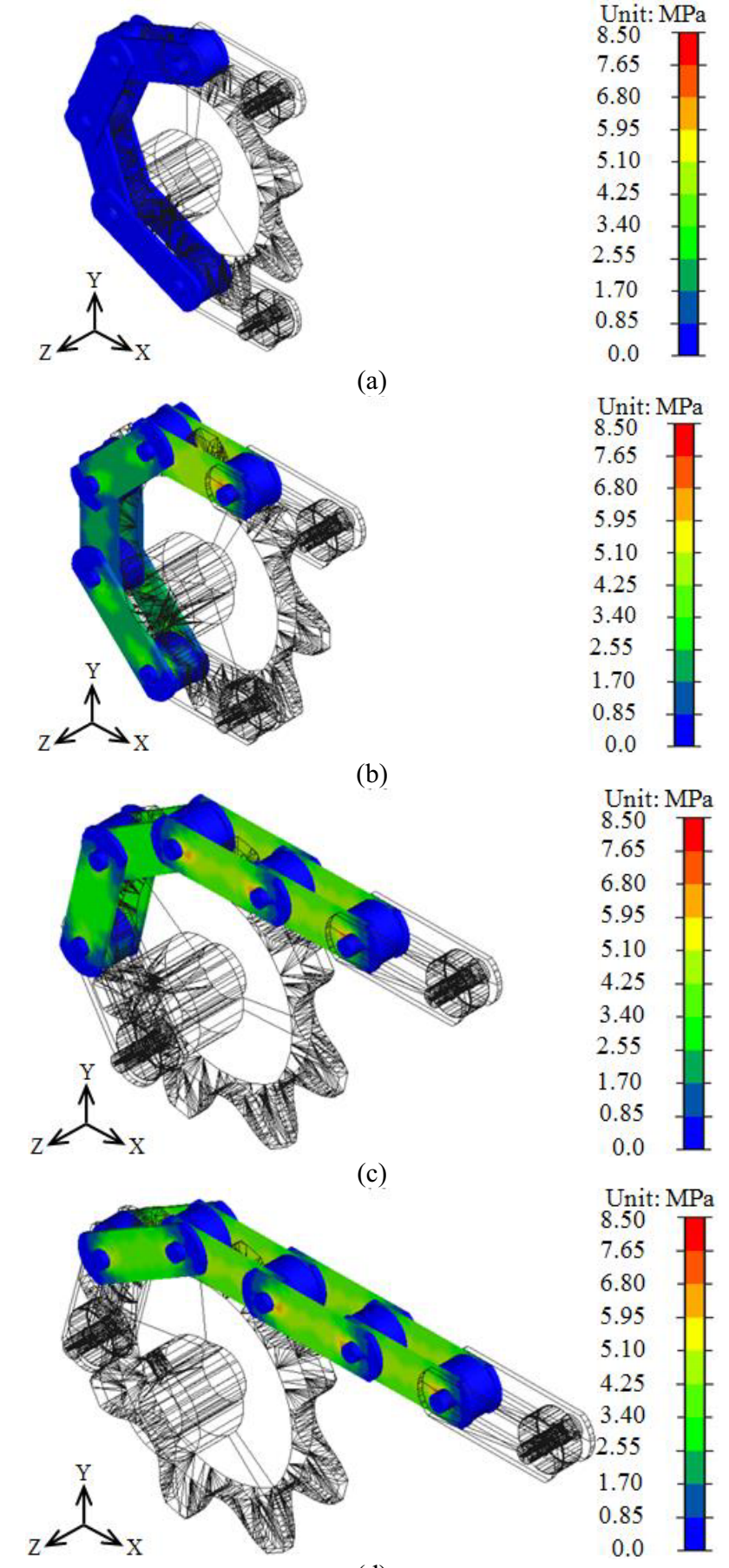

Unit: $\mathrm{MPa}$ 8.50

7.65

6.80

5.95

5.10

4.25

3.40

2.55

1.70

0.85

0.0

Unit: $\mathrm{MPa}$

7.65

6.80

5.95

5.10

4.25 (d)

Figure 9. Sequent images of von mises stress on the roller chain driving at: (a) time $=0.0000 \mathrm{sec}$, (b) time $=0.1200 \mathrm{sec}$, (c) time

$=0.4450 \mathrm{sec}$ and $(\mathrm{d})$ time $=0.7050 \mathrm{sec}$.

70

0.0

roller chain
sec, (c) time

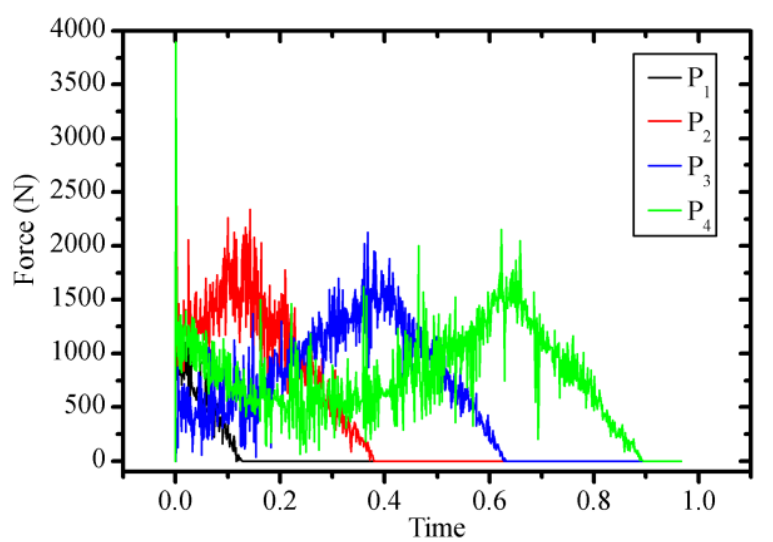

Figure 10. Impact force $\mathrm{P}_{1}, \mathrm{P}_{2}, \mathrm{P}_{3}$, and $\mathrm{P}_{4}$ of roller no. 2, 3, 4 and 5 , respectively.

\section{Conclusions}

The dynamic load distribution in a roller chain drive system was simulated with integration of FEM and MBS. The MFBD method result had been compared with analytical method and obtained an average error of $12.32 \%$. The impact force and von mises stress were the advance result of the MFBD method which could be used to analyze chain strength under dynamic simulation. The magnitude of maximum force and the failure limit of the roller chain were investigated obviously. The MFBD simulation would be useful and advance to design and predict strength of the roller chain drive system for the producing line in a further work.

\section{References}

1. J.L. Wright, Standard Handbook of Chains, second ed. (CRC Press, Florida, 2005)

2. Ç. Özes, M. Demirsoy, Compos. Struct. 69 (2005)

3. A. Bravo, D. Koffi, L. Toubal, F. Erchiqui, Eng. Fail. Anal. 58 (2015)

4. C. Yabing, G. Haitao, F. Zhenming, W. Nen, L. Lei, W. Yang, Chin. J. Mech. Eng. 28, 1 (2015)

5. H. Junzhou, Y. Shiqiang, Y. Jing, L. Tao, The Open Mechanical Engineering J. 7 (2013)

6. C.J. Park, G. Gschwendtner, J. Mech. Sci. Technol. 29, 7 (2015)

7. F. Lin, D. Changlong, G. Kuidong, Adv. Mat. Res. 338 (2011)

8. G. Liu, B. Xu, X. Jiao, T. Zhen, Chinese J. Aronaut. 27, 5 (2014)

9. O. Wallrapp, S. Wiedemann, Nonliner Dynam. 34 (2003)

10. R.N. Mohammad, M.M. Kurt, Mech. Mach. Theory. 18, 5 (1983)

11. R.G. Budynas, J.K. Nisbett, Shigley's Mechanical Engineering Design, ninth ed. (McGraw-Hill, New York, 2011)

12. C.W. Gear, Commun. Acm.14, 3 (1971) 